\title{
An assessment of canine ectoparasiticide administration compliance in the United States based on timing of ectoparasiticide purchases recorded in veterinary hospital transactions.
}

Robert Philip Lavan ( $\sim$ robert.lavan@merck.com )

Merck Animal Health https://orcid.org/0000-0002-8014-8851

Dorothy Normile

Merck Sharp and Dohme Animal Health Germany: MSD Animal Health GmbH

Imran Husain

Celeritas Solutions LLC

Amita Singh

Baruch College Zicklin School of Business

Robert Armstrong

Merck Animal Health

Kathleen Heaney

Consultant

\section{Research}

Keywords: Adherence, Dog, Dosing gap, Ectoparasiticide, Doses plus gap period, Purchase Gap

Posted Date: June 16th, 2021

DOI: https://doi.org/10.21203/rs.3.rs-619965/v1

License: (c) (i) This work is licensed under a Creative Commons Attribution 4.0 International License. Read Full License 


\section{Abstract}

Background: This study evaluated the timing of dog owner ectoparasiticide purchases to estimate administration compliance and assess the consequent impact of dose purchase gaps on the proportion of time that dogs are protected over a 12-month period.

Methods: Ectoparasiticide purchase transactions over a 12-month period were evaluated for dogs from 626 U.S. veterinary hospitals to determine dose purchase timing and identify consequent gaps between dose administration. Orally administered prescription ectoparasitic medications with active ingredients from the isoxazoline family (afoxolaner, fluralaner, lotilaner, or sarolaner) are included in the analysis. A period was calculated for each of the four isoxazoline-containing medications that represented the duration of protection provided by two doses of ectoparasiticide plus the average gap between these two doses. The maximum percentage of time possible for ectoparasiticide protection for this aggregate period was then calculated for each active.

Results: Ectoparasiticide transaction records were analyzed for 506,637 dogs. Of these, $43 \%$ of dog owners purchased just one dose over the 12 months. If a dog owner purchased more than one dose, then the timing of these transactions could create a time gap between the completion of ectoparasite protection from the first dose and onset of protection from the subsequent purchase and administration of the second dose. Such gaps were observed in purchases made by $31-65 \%$ of dog owners depending on the selected active ingredient and number of doses. The average gap duration between dose purchases was calculated for all possible dose combinations over 12 months of ectoparasite protection. Time gaps between the first and second doses are as follows: for sarolaner (20.3 weeks), afoxolaner (12.9 weeks), fluralaner (12.8 weeks), and lotilaner (8.9 weeks). The proportion of time when protection was provided during the aggregate period between administration of the first and second doses was fluralaner $65 \%$, lotilaner $49 \%$, afoxolaner $40, \%$ and sarolaner $30 \%$.

Conclusions: Dog owner ectoparasiticide purchase transactions show that there are time gaps between doses leading to reduced ectoparasite protection. The longer re-administration interval of fluralaner, which results from its extended duration, results in dog owners gaining the greatest proportion of ectoparasite protection time compared with shorteracting monthly re-treatment medications.

\section{Background}

Ectoparasites, most commonly Ctenocephalis felis felis and Ctenocephalis canis, and multiple tick species are a common problem for dogs worldwide [1-5]. These ectoparasites cause discomfort, blood loss and can transfer canine vector-borne pathogens which can also be zoonoses [6-13]. These parasitic vectors are active all year, even in temperate climates, and are increasing their range and frequency of occurrence [14-18]. Many veterinarians and veterinary organizations recommend flea and tick preventive medication administration to dogs and cats year-round $[1,2,4,9,19$, 20].

Pet owners are concerned about ectoparasites and vector-borne pathogens with ever-increasing online searching for relevant information $[6,21]$. Yearly, pet owners purchase 5.2 billion US dollars in ectoparasiticidal products to protect their pets from these pests [22]. Many of these products are highly effective against fleas, ticks, and other ectoparasites when administered correctly with re-administration according to the recommended treatment schedule based on their duration of action [23-31]. Unfortunately, pet owners often fail to re-administer ectoparasiticides according to the label recommended re-treatment schedule as has been evidenced by their failure to purchase sufficient ectoparasiticide doses to adhere to veterinarian recommendations, either continuously throughout the year or seasonally [20, 32-35]. In a survey of 30,020 dogs in Spain, the number of months of flea and tick protection purchased annually was just 2.9 to 
4.3 months depending on the product purchased [32]. In another survey of 231,565 dogs from the U.S., annual monthly purchases of flea and tick products were only 3.3 to 5.7 months of protection [33]. These studies clearly show that dog owners fall short in purchasing the quantities of flea and tick medication necessary to meet veterinarian recommendations for effective flea and tick control [32,33]. However, these studies did not report the timing of dog owner ectoparasiticide purchases or dates of administration. Yet, timely and regular administration of ectoparasiticide medication in a manner consistent with veterinarian recommendations and package insert directions is essential for optimal efficacy and effective ectoparasite control $[12,36,37,38]$. The timely administration of ectoparasiticides doses is key to successful ectoparasite elimination [8, 12,36-38]. Studies have demonstrated that $2-3$ months of continual ectoparasiticides treatment is needed to eliminate a flea infestation $[25-27,31,38]$. Delayed doses or missed doses can interrupt the delivery of continuous ectoparasiticidal therapy, allowing the ectoparasite population to rebound in the home environment. To the pet owner, this rebound may appear as a rapid re-infestation and may cause them to question the product efficacy as well as the veterinarian's recommendation.

Gaps in time between the administration of ectoparasiticide doses can result when either the ectoparasiticidal product is purchased in more than one transaction per year or when the pet owner delays administration of subsequent doses beyond the expiration of the period of efficacy of the previous dose. Unfortunately, there is no easy way to accurately assess home medication administration in a large population of pet owners. Transaction analysis does allow an estimation of the best-case administration of medications by assuming that the medication was given on the date of purchase.

The aim of this study was to use a large transaction database to evaluate dog owner ectoparasiticide purchase timing and estimate adherence with veterinary recommendations for flea and tick protection given to dogs. The study examined the total number of doses and months of protection purchased in a 12-month period, as well as the timing of those purchases, which would allow an estimate of the proportion of time that owners provide ectoparasiticide protection. Ectoparasiticide purchases and time gaps between these purchases can provide insight into these parameters. A secondary aim was to compare the impact of ectoparasiticide purchase gaps when a longer 12-week duration ectoparasiticide (Bravecto, Merck Animal Health, Madison, NJ, USA) is prescribed compared with monthly duration ectoparasiticides.

\section{Methods}

Dog owner ectoparasiticide transaction records from U.S. veterinary hospitals were analyzed to determine purchase intervals and calculate time gaps between dose purchases. Time gaps between ectoparasiticide dose purchases were used to calculated timely medication administration. A purchase gap was declared when the second or subsequent dose of medication was purchased at a time after completion of the recommended duration of efficacy of the first dose, as described in the package insert (PI). The duration of efficacy was considered to be 4.3 weeks for products intended to be re-dosed monthly and 12 weeks for fluralaner. Dog owners were assumed to have administered medication on the date of purchase, therefore, the calculated gap represents the smallest potential time gap between administered doses. A measurable time gap can be detected when pet owners purchase medication in two or more transactions per year. The gap could not be measured between administered doses when the dog owner either purchased multiple doses at the same time or purchased one or more subsequent doses before the conclusion of the period of efficacy of the previous dose. The data were analyzed to calculate the proportion of dog owners who purchased a single dose per year and the proportion who purchased multiple (>1) doses per year, with a detectable time gap between doses.

Transaction data for ectoparasiticide purchases made for individual dogs from 626 veterinary hospitals throughout the U.S. were examined retrospectively from January 1, 2017 through December 31, 2019. Data records were masked to conceal the identity of both the veterinary hospital and the dog owner by using unique numeric identifiers for the dog 
that allowed each record to be associated with an individual animal. Dog demographic data, including age and body weight, were also collected and summarized. Purchases of four different prescription isoxazoline ectoparasiticide medications were included, afoxolaner (NEXGARD® Chewables, Boehringer Ingelheim Animal Health USA, Duluth GA), fluralaner (BRAVECTO ${ }^{\circledR}$ Chew, Merck Animal Health, Madison NJ,USA), lotilaner (CREDELIO ${ }^{\circledR}$ Chewable Tablets, Elanco, Greenfield, IN) and sarolaner (SIMPARICA® Chewables, Zoetis, Kalamazoo, MI).

To permit comparative analysis, client transactions were limited to those who stayed with the same brand over the 12month period. Each transaction record included the date, product - including presentation - and the quantity purchased. Presentations could include single packs, single doses, multi-packs, and/or multiple doses for each product.

Transaction records included were for ectoparasite medication sales made by the hospital to the client in the name of a single patient.

The study period for each client was defined as the 12 months following their initial purchase of an ectoparasiticide. Dogs were included if purchase records were available for the 12 months following the initial purchase, regardless of whether more product was purchased or not. Any doses returned to the hospital for credit were excluded. The retreatment interval for each ectoparasiticide was used to calculate the gaps based on 12-week dosing for fluralaner and monthly (4.3 weeks) dosing for the 3 other medications. Monthly products could have a maximum of 12 purchases and fluralaner could have a maximum of 5 purchases for administration within a single 12-month period. The label for fluralaner also specifies an 8-week dosing interval for protection against Amblyomma americanum which requires a maximum of 7 purchases for 12 months of protection.

Each transaction could include the purchase of one or more doses for each product. Because of the purchase gap, each pair of transactions potentially resulted in variable durations of ectoparasiticide protection. Following completion of the protection period of the first dose, there was the possibility of a period of time before the dog owner purchased the next dose. Gaps in protection were calculated based on the purchase dates for each product dose. For a purchase of a single dose, the purchase date was also the "administration" date for that dose with a protection end date calculated based on the product label recommended re-administration interval. For a single purchase of multiple doses, the administration date of the first dose was the purchase date and the administration dates for remaining doses were set based on the recommended re-administration interval with the assumption that doses were administered consecutively when due. For dog owners with multiple purchase records per year, potentially with a variable number of doses at each purchase, the same assumptions were applied to each purchase record. This analysis assumes that each dose was administered to the dog on the date of purchase and at the correct consecutive interval(s) when multiple doses were purchased. This assumption provides an optimal estimate of timely re-administration of ectoparasiticide doses. If a dog owner deferred giving either the first or subsequent dose(s) then the gap could have been larger than calculated in this analysis.

The total doses purchased were determined for each dog for the entire 12-month period and the gaps between dose administrations were calculated based on purchase dates. These possibilities were used to prepare a matrix that captured all possible dose-gap combinations. For example, fluralaner users could have up to 5-7 doses administered within 12 months and therefore all possible gaps include "Dose 1-2", "Dose 2 - 3", "Dose 3-- 4" and "Dose 4 - 5". Monthly products users could have up to 12 doses administered and all possible dose gaps could include "Dose 1 - 2", "Dose 2 - 3", and so on up to "Dose $11-12$ ". The dose gaps for each possible interval were combined across all of the annual purchased doses for each active ingredient and then used to calculate the average gap in weeks for each dose interval.

A "doses plus gap" period was created for each 2-dose period and defined as the time duration encompassing the ectoparasite protection interval for the two doses plus the average gap between these doses. The percentage of time when ectoparasite protection was available could then be calculated for each "doses plus gap" using the recommended 
redosing interval for each product ( 8 or 12 weeks for fluralaner and 4.3 weeks for the other actives). Dogs would be considered to be unprotected against ectoparasites during the gap portion.

Finally, statistical summaries were created for the age and weight of patients within the products being compared. Mean, range, and standard error of the mean for age and weight of patient dogs were calculated within the products being compared. Means were compared across groups using a t-test with a significance set at $P<0.05$.

\section{Results}

Ectoparasiticide transaction records for four prescription flea and tick products were obtained from veterinary hospitals from across the United States (Table 1).

Table 1. Prescription flea and tick products identified in transaction records obtained in a study of administration gaps

\begin{tabular}{|c|c|c|c|c|c|}
\hline \multirow[t]{2}{*}{ Brand Name } & \multirow[t]{2}{*}{ Manufacturer } & \multirow{2}{*}{$\begin{array}{c}\text { Active } \\
\text { ingredients }\end{array}$} & \multicolumn{2}{|c|}{ Indications } & \multirow{2}{*}{$\begin{array}{l}\text { Redosing } \\
\text { interval }\end{array}$} \\
\hline & & & Fleas & Ticks & \\
\hline BRAVECTO ® Chews & $\begin{array}{l}\text { Merck Animal Health, Madison, NJ, } \\
\text { USA }\end{array}$ & Fluralaner & $\mathrm{X}$ & $\mathrm{X}$ & $\begin{array}{c}8-12 \\
\text { weeks }\end{array}$ \\
\hline CREDELIO ${ }^{\circledR}$ & ELANCO Animal Health & Lotilaner & $\mathrm{X}$ & $\mathrm{X}$ & Monthly \\
\hline $\begin{array}{l}\text { NEXGARD }{ }^{\circledR} \\
\text { Chewables }\end{array}$ & Boehringer Ingelheim & Afoxolaner & $\mathrm{X}$ & $\mathrm{X}$ & Monthly \\
\hline $\begin{array}{l}\text { SIMPARICA }{ }^{\circledR} \\
\text { Chewables }\end{array}$ & Zoetis & Sarolaner & $\mathrm{X}$ & $\mathrm{X}$ & Monthly \\
\hline
\end{tabular}

${ }^{a}$ Bravecto Chew is labeled for 12-week redosing for most indications, with 8-week redosing indicated when necessary for Amblyomma americanum.

Participating hospitals were located in the Southeast $(n=345 ; 55 \%)$, Mid-west $(n=110 ; 18 \%)$, Southcentral $(n=96 ; 15 \%)$, West $(n=39 ; 6 \%)$ and Northeast $(n=36 ; 6 \%)$ regions of the United States. Dogs ranged from 6 months to 20 years of age with an average overall age of 6.9 years and their weight ranged from 1.3 to 60.0 kilograms with an overall average weight of $18.2 \mathrm{~kg}$. Because of the large number of dogs in each group, all means for age and weight were significantly different from each other (Paired t-test, $P<0.0001$ )

Table 2. Age and weight of dogs identified through owner purchase transaction records

\begin{tabular}{|c|c|c|c|c|c|}
\hline & $\begin{array}{l}\text { Afoxolaner } \\
(n=248393)\end{array}$ & $\begin{array}{c}\text { Fluralaner } \\
(n=170792)\end{array}$ & $\begin{array}{c}\text { Lotilaner } \\
(\mathrm{n}=16536)\end{array}$ & $\begin{array}{c}\text { Sarolaner } \\
(n=70916)\end{array}$ & $\begin{array}{c}\text { All Dogs* } \\
(n=506637)\end{array}$ \\
\hline $\begin{array}{l}\text { Mean Age } \\
\text { (SEM) }\end{array}$ & $6.6(0.01)$ & $7.6(0.01)$ & $4.7(0.03)$ & $7.0(0.02)$ & $6.9(0.01)$ \\
\hline $\begin{array}{l}\text { Median Age } \\
\text { (Range) }\end{array}$ & $\begin{array}{c}6.4 \\
(0.5-20.0)\end{array}$ & $\begin{array}{c}6.9 \\
(0.5-20.0)\end{array}$ & $\begin{array}{l}2.5 \\
(0.5- \\
19.8)\end{array}$ & $\begin{array}{c}6.3 \\
(0.5-20.0)\end{array}$ & $\begin{array}{c}{ }^{6.1} \\
(0.5- \\
20.0)\end{array}$ \\
\hline Mean wt (SEM) & $17.6(0.03)$ & $19.2(0.04)$ & $\begin{array}{c}15.8 \\
(0.09)\end{array}$ & $18.7(0.06)$ & $18.2(0.02)$ \\
\hline $\begin{array}{l}\text { Median wt } \\
\text { (Range) }\end{array}$ & $\begin{array}{c}14.5 \\
(1.8-55.0)\end{array}$ & $\begin{array}{c}17.6 \\
(2.0-55.9)\end{array}$ & $\begin{array}{c}13.1 \\
(2.8-45.5)\end{array}$ & $\begin{array}{c}16.5 \\
(1.3-60.0)\end{array}$ & $\begin{array}{c}15.7 \\
(1.3-59.9)\end{array}$ \\
\hline
\end{tabular}

${ }^{*}$ Group mean ages and weights are significantly different $\mathrm{p}<0.00001$. 
More than half of dog owners obtained only 1-3 months of flea and tick protection, with less than $1 / 3$ of owners obtaining 4-6 months of protection and less than $20 \%$ obtaining 7-12 months of protection (Tables 3 and 4 ). This ectoparasiticide purchasing record is inconsistent with veterinarian recommendations for nearly year-round flea and tick protection $[1,2,4,9,19,20]$.

Table 3. Dog ectoparasite protection intervals by product based on doses obtained by the dog owner recorded in veterinary hospital transaction records.

\begin{tabular}{|c|c|c|c|c|}
\hline $\begin{array}{l}\text { Flea and tick protection duration purchased within } \\
\qquad 12 \text { months }\end{array}$ & $\begin{array}{l}\text { Afoxolaner } \\
(\mathrm{n}=248393)\end{array}$ & $\begin{array}{c}\text { Fluralaner } \\
(\mathrm{n}= \\
170792)\end{array}$ & $\begin{array}{l}\text { Lotilaner } \\
(\mathrm{n}=16536\end{array}$ & $\begin{array}{l}\text { Sarolaner } \\
(\mathrm{n}=70916)\end{array}$ \\
\hline 1-6 months/year & $87.0 \%$ & $81.8 \%$ & $88.4 \%$ & $83.7 \%$ \\
\hline 1-3 months/year & $66.5 \%$ & $54.0 \%$ & $70.0 \%$ & $57.3 \%$ \\
\hline 4-6 months/year & $20.5 \%$ & $27.8 \%$ & $18.4 \%$ & $26.4 \%$ \\
\hline 7-12 months/year & $13.0 \%$ & $18.2 \%$ & $11.6 \%$ & $16.3 \%$ \\
\hline
\end{tabular}

Nearly half (43\%) of all dog owners obtained just one dose of ectoparasiticide in the 12-month period regardless of flea/tick medication purchased. Similarly, close to half (42\%) of dog owners who obtained more than one dose allowed time gaps between their purchase transactions of flea and tick medication (Table 4). The proportion of transactions that created a protection gap tended to decrease with increasing numbers of doses purchased because the average length of these gaps tended to decrease. However, for dog owners who obtained more than 6 doses of the monthly administered products, the proportion of transactions with gaps increased between doses 6 and 7 (Table 4). The longest average purchase gap duration was calculated for dog owners obtaining sarolaner (3.6 to 20.3 weeks) with shorter gaps for fluralaner (3.3 to 12.8 weeks), afoxolaner (2.1 to 12.9 weeks) and lotilaner (1.6 to 8.9 weeks) (see Table 5).

Table 4. Dog owner ectoparasiticide purchases with and without gaps, including average gap duration between doses. 


\begin{tabular}{|c|c|c|c|c|}
\hline Doses purchased & $\begin{array}{l}\text { Fluralaner }^{\mathrm{a}} \\
(\mathrm{n}=170792)\end{array}$ & $\begin{array}{l}\text { Afoxolaner } \\
(\mathrm{n}=248393)\end{array}$ & Sarolaner $(n=70916)$ & $\begin{array}{c}\text { Lotilaner } \\
(\mathrm{n}=16536)\end{array}$ \\
\hline $\begin{array}{l}1 \text { dose } \\
\text { Total N (\% of total) }\end{array}$ & $\begin{array}{l}92153 \\
(54 \%)\end{array}$ & $\begin{array}{l}96151 \\
(39 \%)\end{array}$ & $\begin{array}{l}22416 \\
(32 \%)\end{array}$ & $\begin{array}{l}7401 \\
(45 \%)\end{array}$ \\
\hline 2-12 doses (\%) & $(46 \%)$ & $(61 \%)$ & $(68 \%)$ & $(55 \%)$ \\
\hline Total purchasing $>1$ dose & 78639 & 152242 & 48500 & 9135 \\
\hline $\begin{array}{c}\text { No Gap } \\
\text { N }(\%)\end{array}$ & $\begin{array}{r}27435 \\
(35 \%)\end{array}$ & $\begin{array}{c}104945 \\
(69 \%)\end{array}$ & $\begin{array}{l}28078 \\
(58 \%)\end{array}$ & $\begin{array}{l}5587 \\
(61 \%)\end{array}$ \\
\hline $\begin{array}{c}\text { Purchase Gap } \\
\text { N (\%) }\end{array}$ & $\begin{array}{l}51204 \\
(65 \%)\end{array}$ & $\begin{array}{r}47297 \\
(31 \%)\end{array}$ & $\begin{array}{l}20422 \\
(42 \%)\end{array}$ & $\begin{array}{l}3548 \\
(39 \%)\end{array}$ \\
\hline Purchased $\geq 2$ doses & 78639 & 152242 & 48500 & 9135 \\
\hline Total with 1-2 dose gap & 42638 & 28527 & 11049 & 2041 \\
\hline \% with gap & $54 \%$ & $19 \%$ & $23 \%$ & $22 \%$ \\
\hline Ave. Gap (Weeks) & 12.8 & 12.9 & 20.3 & 8.9 \\
\hline Purchased $\geq 3$ doses & 31241 & 111420 & 39695 & 6426 \\
\hline Total with 2-3 dose gap & 17543 & 11753 & 6040 & 1214 \\
\hline$\%$ with gap & $56 \%$ & $11 \%$ & $15 \%$ & $19 \%$ \\
\hline Ave. Gap (Weeks) & 8.5 & 9.9 & 16.4 & 6.5 \\
\hline Purchased $\geq 4$ doses & 11742 & 81992 & 29184 & 4943 \\
\hline Total with 3-4 dose gap & 4206 & 12100 & 5641 & 731 \\
\hline$\%$ with gap & $36 \%$ & $15 \%$ & $19 \%$ & $15 \%$ \\
\hline Ave. Gap (Weeks) & 4.8 & 10.1 & 17.6 & 6.4 \\
\hline Purchased $\geq 5$ doses & 1631 & 69702 & 25583 & 4271 \\
\hline Total with 4-5 dose gap & 457 & 4389 & 2416 & 436 \\
\hline$\%$ with gap & $28 \%$ & $6 \%$ & $9 \%$ & $10 \%$ \\
\hline Ave. Gap (Weeks) & 3.3 & 7.0 & 12.9 & 4.4 \\
\hline Purchased $\geq 6$ doses & & 65205 & 23721 & 3912 \\
\hline Total with 5-6 dose gap & & 2455 & 1344 & 230 \\
\hline \% with gap & & $4 \%$ & $6 \%$ & $6 \%$ \\
\hline Ave. Gap (Weeks) & & 5.7 & 10.7 & 4.0 \\
\hline Purchased $\geq 7$ doses & & 31598 & 10020 & 1862 \\
\hline Total with 6-7 dose gap & & 5868 & 4187 & 421 \\
\hline
\end{tabular}

\begin{tabular}{|c|c|c|c|c|}
\hline \% with gap & & $19 \%$ & $42 \%$ & $23 \%$ \\
\hline Ave. Gap (Weeks) & & 9.1 & 19.4 & 9.8 \\
\hline & & & & \\
\hline
\end{tabular}

\begin{tabular}{|l|c|c|c|}
\hline Purchased $\geq 8$ doses & 22302 & 7136 & 1416 \\
\hline Total with 7-8 dose gap & 1246 & 608 & 114 \\
\hline
\end{tabular}

\begin{tabular}{|c|c|c|c|c|}
\hline \% with gap & & $6 \%$ & $9 \%$ & $8 \%$ \\
\hline Ave. Gap (Weeks) & & 4.3 & 8.8 & 3.9 \\
\hline & & & & \\
\hline
\end{tabular}




\begin{tabular}{|c|c|c|c|}
\hline Purchased $\geq$ 9 doses & 18415 & 5876 & 1172 \\
\hline Total with 8-9 dose gap & 703 & 334 & 62 \\
\hline \% with gap & $4 \%$ & $6 \%$ & $5 \%$ \\
\hline Ave. Gap (Weeks) & 3.4 & 8.6 & 3.1 \\
\hline Purchased $\geq 10$ doses & & & \\
\hline Total with 9-10 dose gap & 510 & 332 & 35 \\
\hline \% with gap & $4 \%$ & $7 \%$ & $4 \%$ \\
\hline Ave. Gap (Weeks) & 3.4 & 10.3 & 4.0 \\
\hline & & & \\
\hline Purchased $\geq 11$ doses & 13213 & 3892 & 865 \\
\hline Total with 10-11 dose gap & 137 & 74 & 14 \\
\hline \% with gap & $1 \%$ & $2 \%$ & $2 \%$ \\
\hline Ave. Gap (Weeks) & 2.3 & 6.9 & 2.6 \\
\hline & & & \\
\hline Purchased 12 doses & 12044 & 3478 & 770 \\
\hline Total with 11-12 dose gap & 32 & 16 & 7 \\
\hline \% with gap & $0.3 \%$ & $0.5 \%$ & $1 \%$ \\
\hline Ave. Gap (Weeks) & 2.1 & 3.6 & 1.6 \\
\hline
\end{tabular}

a Fluralaner has a 12-week dosing interval for most parasites on the label, a maximum of 5 doses fluralaner topical purchases were considered for the 12-month period studied. (Note: Up to 7 doses of fluralaner may be required for full year protection in areas where $A$. americanum are of concern.)

For dog owners obtaining fluralaner, the protection proportion calculated for the "doses plus gap" period gradually increased with subsequent doses indicating a greater duration of administered protection and was: $65 \%$ for the period between doses 1 and 2; 74\% for the period 2-3; 83\% for period $3-4$; and, 88\% for period $4-5$ (Table 5). The protection proportion of each 2 dose plus gap period for the monthly administered products was smaller than for fluralaner at the dose intervals for the first 6 doses (Table 5). The protection proportion for all the monthly medications generally increased and the gap size decreased from dose periods 1 to 12 with the exception of dose 6-7 which demonstrated one of the longest gaps between purchases (Table 5).

Table 5. The proportion of each 2-dose plus purchase gap interval with and without ectoparasite protection. 


\begin{tabular}{|c|c|c|c|c|c|c|c|c|c|c|}
\hline \multirow{3}{*}{$\begin{array}{l}\text { ection } \\
\text { ltion } \\
\text { iinal } \\
\text { ths) }\end{array}$} & \multirow{3}{*}{$\begin{array}{c}\text { Product } \\
\\
\text { Fluralaner } \\
\text { Gaps }\end{array}$} & \multicolumn{2}{|c|}{$\begin{array}{l}\text { Fluralaner }^{\mathrm{a}} \\
\text { (12-week } \\
\text { dosing) }\end{array}$} & \multirow[t]{2}{*}{ Product } & \multicolumn{2}{|c|}{ Afoxolaner } & \multicolumn{2}{|c|}{ Lotilaner } & \multicolumn{2}{|c|}{ Sarolaner } \\
\hline & & $\begin{array}{l}\text { Doses } \\
\text { plus gap } \\
\text { period }^{\mathrm{a}} \\
\text { (weeks) }^{\text {(weeks }}\end{array}$ & $\begin{array}{l}\% \text { of time } \\
\text { protected }\end{array}$ & & $\begin{array}{l}\text { Doses } \\
\text { plus gap } \\
\text { period }^{\mathrm{a}} \\
\text { (weeks) }^{\text {(weeks }}\end{array}$ & $\begin{array}{l}\% \text { of time } \\
\text { protected }\end{array}$ & $\begin{array}{l}\text { Doses } \\
\text { plus gap } \\
\text { period }^{\mathrm{a}} \\
\text { (weeks) }^{\text {(weeks }}\end{array}$ & $\begin{array}{l}\% \text { of time } \\
\text { protected }\end{array}$ & $\begin{array}{l}\text { Doses } \\
\text { plus gap } \\
\text { period }^{\mathrm{a}} \\
\text { (weeks) }^{\text {(weeks }}\end{array}$ & $\begin{array}{l}\% \text { of time } \\
\text { protected }\end{array}$ \\
\hline & & & & $\begin{array}{c}\text { Monthly } \\
\text { Product } \\
\text { Gaps }\end{array}$ & & & & & & \\
\hline 1 & No Gap & & & No Gap & & & & & & \\
\hline 2 & & & & $\begin{array}{c}\text { Dose } 1- \\
2\end{array}$ & 21.5 & 40 & 17.5 & 49 & 28.9 & 30 \\
\hline 3 & & & & $\begin{array}{c}\text { Dose } 2- \\
3\end{array}$ & 18.5 & 46 & 15.1 & 57 & 25.0 & 34 \\
\hline 4 & $1-2$ & 36.8 & 65 & $\begin{array}{c}\text { Dose } 3- \\
4\end{array}$ & 18.7 & 46 & 15.0 & 57 & 26.2 & 33 \\
\hline 5 & & & & $\begin{array}{c}\text { Dose } 4- \\
5\end{array}$ & 15.6 & 55 & 13.0 & 66 & 21.5 & 40 \\
\hline 6 & & & & $\begin{array}{c}\text { Dose } 5- \\
6\end{array}$ & 14.3 & 60 & 12.6 & 68 & 19.3 & 45 \\
\hline 7 & $2-3$ & 32.5 & 74 & $\begin{array}{c}\text { Dose } 6- \\
7\end{array}$ & 17.7 & 49 & 18.4 & 47 & 28.0 & 31 \\
\hline 8 & & & & $\begin{array}{c}\text { Dose 7- } \\
8\end{array}$ & 12.9 & 67 & 12.5 & 69 & 17.4 & 49 \\
\hline 9 & & & & $\begin{array}{c}\text { Dose } 8- \\
9\end{array}$ & 12.0 & 72 & 11.7 & 74 & 17.2 & 50 \\
\hline 10 & & 28.8 & 83 & $\begin{array}{c}\text { Dose } 9- \\
10\end{array}$ & 12.0 & 72 & 12.6 & 68 & 18.9 & 46 \\
\hline 11 & $4-5^{ \pm}$ & 27.3 & 88 & $\begin{array}{c}\text { Dose } \\
10-11\end{array}$ & 10.9 & 79 & 11.2 & 77 & 15.5 & 55 \\
\hline 12 & & & & $\begin{array}{c}\text { Dose } \\
11-12\end{array}$ & 10.7 & 80 & 10.2 & 84 & 12.2 & 70 \\
\hline
\end{tabular}

a "Doses plus gap" period is the time encompassing the label duration of two doses of an ectoparasiticide medication including the average gap between purchases of the two doses, measured in weeks. For afoxolaner, lotilaner and sarolaner, the single dose duration of efficacy was 4.3 weeks. For fluralaner the single dose duration of efficacy was 12 weeks per label indications for most parasites.

\pm 4-5 doses of fluralaner provides ectoparasiticide protection beyond the 12-month study duration.

The impact of purchase gaps on the percentage of time that ectoparasite protection was available is shown for owners who purchased 1-3 months and 1-6 months of flea and tick medication in a year, the most common amount of protection purchased (Table 3). The fluralaner dosing interval is 12 weeks, therefore 1 and 2 doses ( 2.8 months and 5.6 months) of fluralaner were compared to 3 and 6 doses of the monthly duration products afoxolaner, sarolaner, and lotilaner. Because fluralaner is approved in the United States for an 8-week dosing interval when necessary for the control of Amblyomma americanum, 2 and 4 doses of fluralaner were also compared to 3 and 6 doses of the monthly duration products. The total duration of the 3-month and 6-month "doses plus gap" period for each product are shown (Figures $1 \mathrm{a}-\mathrm{b}$ ) and for each of these periods, the percentage of time when ectoparasiticide protection could be available was determined and compared.

The percentage of ectoparasite protection available during use of the first 12 weeks or 3 months of the product purchased was $100 \%$ for fluralaner with the 12-week dosing interval (12 weeks or 2.8 months) and $56 \%$ with the 
fluralaner 8-week dosing interval, 36\% for afoxolaner, $26 \%$ for sarolaner and $46 \%$ for lotilaner (Fig 1a). The percentage of ectoparasite protection available when dog owners purchased up to 6 months of medication was $65 \%$ for fluralaner with the 12-week dosing interval and 55\% with the fluralaner 8-week dosing interval, 36\% for afoxolaner, $25 \%$ for sarolaner and $46 \%$ for lotilaner (Fig 1b).

\section{Discussion}

Timely and regular administration of ectoparasiticide medication in a manner consistent with veterinarian recommendations and package insert directions is essential for optimal effectiveness and effective ectoparasite control [12,36-38]. Prior studies have shown that dog owners fall short in purchasing the quantities of flea and tick medication necessary to meet veterinarian recommendations for effective flea and tick control [32,33]. The present study of ectoparasiticide purchase records for 506,637 dogs confirms these previous findings with $43 \%$ of dog owners purchasing just 1 single dose of ectoparasiticide medication in a 12-month period, and $54-70 \%$ of dog owners purchasing just 1-3 months of the ectoparasiticide protection. The present study also shows that of dog owners purchasing more than one dose of ectoparasiticide, $42.4 \%$ delayed purchases of subsequent doses beyond the efficacy duration of the prior dose noted in the manufacturer's product insert making timely redosing impossible

Gaps in timely ectoparasiticide purchases represent times when dogs may not be protected against fleas and ticks. In addition, if an established ectoparasite population was not eliminated by prior treatment, then a purchase gap interrupts the treatment and may allow that parasite population to recover. Also, treatment gaps lead to an increased risk for prolonged ectoparasite infestation and potential exposure to vector-borne pathogens [36,38].

For this study, medication administration was assumed to have occurred on the day of purchase. The owners may have delayed the dose administration for days, weeks, or longer following purchase, but the actual day of administration was not verified in this study involving a large dog owner population. Therefore, the timing of medication administration presented here represents the best possible amount of time between the delivery of consecutive doses. However, studies in both human and veterinary medicine have shown that timely administration frequently fails to occur even when all necessary doses are dispensed at once [35, 39-44]. Therefore, it is possible that the actual time to administration was longer than reported here, and delays in administration may have occurred even when multiple doses of medication were purchased at one time.

Considering the realities of dog owner ectoparasiticide purchases, the present study examined the value of the longer duration fluralaner medication compared to monthly administered flea and tick medications. The benefits come from the length of time that a single fluralaner dose protects against ectoparasites as well as the reduced number of doses that need to be given to provide protection for a given period of time. The facts that owners allow gaps to occur in their flea and tick medication purchases and that there is a need for more frequent redosing intervals for monthly administered products result in smaller proportions of time when dogs receive ectoparasite protection than is seen with longer duration medication. More frequent gaps in dosing for monthly products can reduce their efficacy in accomplishing the goal of ectoparasite elimination and consistent ectoparasite control.

When dog owners purchase more than one month of flea and tick medication, they often purchase either 3 months or 6 months of protection. If the dog owners' goal is to provide continuous protection for these 3 or 6 months, then their dog can get 12 weeks of continuous protection with one dose of fluralaner or with multiple one month intervals using shorter duration ectoparasiticides. The shorter duration products require repeated on-time dosing to achieve the same continuous protection as one dose of fluralaner. The gap analysis demonstrates that dog owners buying monthly products usually do not achieve the goal of on-time dosing with inter-dose intervals that range from 9.9 to 12.9 weeks for afoxolaner, 16.4 to 20.3 weeks for sarolaner, and 6.5 to 8.9 weeks for lotilaner. The proportion of time when

Page $10 / 17$ 
ectoparasite protection is provided with the purchase of up to 3 months of product are: $100 \%$ for fluralaner (2.8 months or 12 weeks), $36 \%$ (3 months) for afoxolaner, $26 \%$ (3 months) for sarolaner and $46 \%$ (3 months) for lotilaner (Fig 1a). If a shorter 8-week dosing interval is used for the calculation with fluralaner, then the percentage of time when ectoparasite protection is available is $56 \%$.

Gaps in flea and tick protection seen when dog owners purchase 6 months of annual treatment are shown in Figure 1b. The size of the gaps usually shrinks when dog owners buy more months of protection. This shrinkage may simply be secondary to the effect of purchasing more doses within a dwindling period of possible unprotected time. Owners who purchased two doses of fluralaner obtained 24 weeks of protection with a 12.8-week gap between doses, resulting in their dog being protected from fleas and ticks for $65 \%$ of the "doses plus gaps" interval. The monthly product purchases were spread out by gaps of various sizes that ranged from 4 to 20 weeks between doses and provides protection from fleas and ticks for $36 \%$ of the "doses plus gaps" interval for afoxolaner, $25 \%$ for sarolaner and $46 \%$ for lotilaner. Even if a shorter 8-week dosing interval is used for the calculation with fluralaner, the percentage of the "doses plus gaps" time when ectoparasite protection is available is $55 \%$.

For each of the flea and tick medications dosed monthly, the longest "doses plus gap" interval was between the $6^{\text {th }}$ and $7^{\text {th }}$ dose (Table 5). Manufacturers often package monthly flea and tick medications into packages of 3 or 6 doses. The size of the gap following the $6^{\text {th }}$ dose may be secondary to a delayed repeat purchase following an initial purchase of a single card with 6 doses.

This difference in number and duration of purchase gaps and the resultant percent of time when dogs are protected against ectoparasites has practical implications. Interruptions in ectoparasiticide protection that arise from either gaps in dose purchase timing or other delays in administration can result in a perceived lack of effectiveness if the duration of continuous use is insufficient to eliminate established infestations on the animal, in the home, or in the face of continued parasite exposure. Previous studies have shown that multiple, consecutive doses of afoxolaner, sarolaner, or lotilaner were required to eliminate an established flea infestation, with evidence of the infestation continuing following a single dose [23, 26-28]. A treatment gap between doses of a monthly ectoparasiticide may allow the infesting ectoparasite population to rebound if the population is not eliminated. The longer duration medication, fluralaner, provides ectoparasiticide protection for a duration that provides complete resolution of flea infestation without re-dosing [26].

Studies on patient and pet owner adherence to prescribed treatment regimens in both human and veterinary medicine have shown that simpler, less frequent dosing regimens improve compliance across a variety of therapeutic classes [3949]. The present study similarly demonstrates the benefit of less frequent dosing with a longer duration ectoparasiticide. Dog owners who purchased ectoparasiticides with time gaps between doses, but chose the longer duration product, provided more consecutive weeks of medication, reduced treatment interruptions, and increased the overall percentage of time when ectoparasite protection is available during each "doses plus gap" period than dog owners who purchased a monthly treatment. Such increases in the overall duration of ectoparasite protection with fewer interruptions provided by the longer duration fluralaner medication should improve ectoparasite control, decrease exposure to VBP and provide greater pet owner satisfaction with efforts to remove ectoparasites.

In the United States, dog owners purchase isoxazoline ectoparasiticides with a prescription from a veterinarian. We have seen that veterinarians may recommend up to 12 months of protection for fleas and ticks. The dog owner has the option to purchase one or multiple doses in one or more transactions. Veterinarians expect that dog owners use the doses they purchase and that they apply the next dose when a previous dose has completed its label recommended protection interval. More information is still needed to establish actual owner behavior in administering flea and tick medications at home; however, it is clear that there are delays in ectoparasiticide administration based on veterinary hospital

Page $11 / 17$ 
transaction records. There is a real benefit to the pet owner and the dog when a longer-acting ectoparasiticide is prescribed and this relates directly to the additional week/months of coverage per administered dose with a need for fewer dose administrations throughout the year.

\section{Conclusion}

This study demonstrated that dog owners fail to adhere to veterinarian recommendations for ectoparasiticide protection by purchasing fewer doses of ectoparasiticide than recommended and allowing time gaps between their dose purchases that make adherence to recommended re-administration intervals impossible. Dog owners prescribed a longer duration medication, fluralaner, obtained more consecutive weeks of ectoparasite protection with a larger overall percentage of time when their dogs are protected from ectoparasites compared with monthly re-administration medications.

\section{Abbreviations}

CAPC: Companion Animal Parasite Council; ESCCAP: European Scientific Counsel on Companion Animal Parasites; VBP: vector-borne pathogens; CVBD: Canine vector-borne disease; PI: package insert

\section{Declarations}

\section{Acknowledgments}

\section{Funding}

This work was funded by Merck Animal Health, Madison, NJ, USA.

\section{Availability of data and materials}

The datasets were obtained from a public source (VetInformatics, Inc., Rolling Meadows, III, USA). The analysis was generated during the current study and is not publicly available because this is the proprietary property of Merck \& Co., Inc., Kenilworth, NJ, USA.

\section{Authors' contributions}

$\mathrm{RL}$ wrote the protocol. $\mathrm{RL}, \mathrm{IH}$, and AS performed the data analysis. All of the authors contributed to the interpretation of results as well as the writing and revision of the manuscript. All authors reviewed and approved the final manuscript.

\section{Competing interests}

RL , RA and DN are employees of Merck Sharp \& Dohme Corp., a subsidiary of Merck \& Co., Inc., Kenilworth, NJ, USA. KH is an independent consultant. IH is an employee of Celeritas Solutions LLC. AS is an employee of Baruch College CUNY and a consultant to Celeritas Solutions LLC.

Consent for publication Not applicable.

Ethics approval and consent to participate Data was obtained under a data sharing contract. No live animals were used in this study and medical records were not examined. All transaction records were blinded as to the hospital identity, pet owner's identity and home address.

\section{References}


1. Companion Animal Parasite Council: Companion Animal Parasite Council Recommendations-

Fleas. https://capcvet.org/guidelines/fleas/ (2017). Accessed June 202020.

2. Companion Animal Parasite Council: Companion Animal Parasite Council Recommendations- TICKS https://capcvet.org/guidelines/ticks/ (2017). Accessed June 12020.

3. Dryden MW. Flea and tick control in the 21st century: challenges and opportunities. Vet Dermatol. 2009;20 56:435-40.

4. European Scientific Counsel Companion Animal Parasites ESCoCA: ESCCAP guideline 3: control of ectoparasites in dogs and cats.

https://www.esccap.org/uploads/docs/mjy50wev_0720_ESCCAP_Guideline_GL3_v9_1p.pdf. (2018). Accessed June 20, 2020.

5. Greay TL, Oskam CL, Gofton AW, Rees RL, Ryan UM, Irwin PJ. A survey of ticks (Acari: Ixodidae) of companion animals in Australia. Parasites \& Vectors. 2016;9 1:207.

6. Berrada ZL, Telford SR, 3rd. Burden of tick-borne infections on American companion animals. Top Companion Anim Med. 2009;24 4:175-81.

7. Bitam I, Dittmar K, Parola P, Whiting MF, Raoult D. Fleas and flea-borne diseases. Int J Infect Dis. 2010;14 8:e667-76.

8. Dryden MW, Hodgkins E. Vector-borne diseases in pets: the stealth health threat. Compend Contin Educ Vet. 2010;32 6:E1-4.

9. European Scientific Counsel Companion Animal Parasites ESCoCA: ESCCAP guideline 5: Control of vectorborne diseases in dogs and cats.

https://www.esccap.org/uploads/docs/znkh6j1d_0775_ESCCAP_Guideline_GL5_v8_1p.pdf (2019). Accessed June 1 2020.

10. Otranto D, Dantas-Torres F, Breitschwerdt EB. Managing canine vector-borne diseases of zoonotic concern: part one. Trends Parasitol. 2009;25 4:157-63.

11. Otranto D, Dantas-Torres F, Breitschwerdt EB. Managing canine vector-borne diseases of zoonotic concern: part two. Trends Parasitol. 2009;25 5:228-35.

12. Rust MK. Recent Advancements in the Control of Cat Fleas. Insects. 2020;11 10.

13. Neer TM, Breitschwerdt EB, Greene RT, Lappin MR. Consensus statement on ehrlichial disease of small animals from the infectious disease study group of the ACVIM. American College of Veterinary Internal Medicine. J Vet Intern Med. 2002;16 3:309-15.

14. Little SE, Barrett AW, Nagamori Y, Herrin BH, Normile D, Heaney K, et al. Ticks from cats in the United States: Patterns of infestation and infection with pathogens. Vet Parasitol. 2018;257:15-20.

15. Saleh MN, Sundstrom KD, Duncan KT, lentile MM, Jordy J, Ghosh P, et al. Show us your ticks: a survey of ticks infesting dogs and cats across the USA. Parasit Vectors. 2019;12 1:595.

16. Rochlin I, Toledo A. Emerging tick-borne pathogens of public health importance: a mini-review. J Med Microbiol. 2020;69 6:781-91. 
17. Bouchard C, Dibernardo A, Koffi J, Wood H, Leighton PA, Lindsay LR. N Increased risk of tick-borne diseases with climate and environmental changes. Can Commun Dis Rep. 2019;45 4:83-9.

18. Sonenshine DE. Range Expansion of Tick Disease Vectors in North America: Implications for Spread of TickBorne Disease. Int J Environ Res Public Health. 2018;15 3.

19. Lavan R, Armstrong, R., Lipworth, K., Normile, N. and Newbury, H. Flea and tick treatment satisfaction, preference and adherence of dog owners in the United States, United Kingdom and Australia who treated their dog with fluralaner. Open Vet J 2020;10 2:135-43.

20. Lavan RP, Tunceli K, Zhang D, Normile D, Armstrong R. Assessment of dog owner adherence to veterinarians' flea and tick prevention recommendations in the United States using a cross-sectional survey. Parasit Vectors. 2017;10 $1: 284$.

21. Scheerer C, Rüth M, Tizek L, Köberle M, Biedermann T, Zink A. Googling for Ticks and Borreliosis in Germany: Nationwide Google Search Analysis From 2015 to 2018. J Med Internet Res. 2020;22 10:e18581.

22. Research and Markets: Flea and Tick Products - Global Market Trajectory \& Analytics. https://www.researchandmarkets.com/reports/5141344/flea-and-tick-products-global-market-trajectory (2020). Accessed January 262021.

23. Cavalleri D, Murphy M, Seewald W, Drake J, Nanchen S. A randomised, blinded, controlled field study to assess the efficacy and safety of lotilaner tablets $\left(\right.$ Credelio $\left.^{\mathrm{TM}}\right)$ in controlling fleas in client-owned dogs in European countries. Parasites \& Vectors. 2017;10 1:526.

24. Cavalleri D, Murphy M, Seewald W, Drake J, Nanchen S. A randomized, controlled study to assess the efficacy and safety of lotilaner (Credelio ${ }^{\text {TM }}$ ) in controlling ticks in client-owned dogs in Europe. Parasit Vectors. 2017;10 1:531.

25. Dryden MW, Canfield MS, Herrin BH, Bocon C, Bress TS, Hickert A, et al. In-home assessment of flea control and dermatologic lesions in dogs provided by lotilaner (Credelio(ß)) and spinosad (Comfortis(®)) in west central Florida. Vet Parasitol X. 2019;1:100009.

26. Dryden MW, Canfield MS, Kalosy K, Smith A, Crevoiserat L, McGrady JC, et al. Evaluation of fluralaner and afoxolaner treatments to control flea populations, reduce pruritus and minimize dermatologic lesions in naturally infested dogs in private residences in west central Florida USA. Parasit Vectors. 2016;9 1:365.

27. Dryden MW, Canfield MS, Niedfeldt E, Kinnon A, Kalosy K, Smith A, et al. Evaluation of sarolaner and spinosad oral treatments to eliminate fleas, reduce dermatologic lesions and minimize pruritus in naturally infested dogs in west Central Florida, USA. Parasit Vectors. 2017;10 1:389.

28. Karadzovska D, Chappell K, Coble S, Murphy M, Cavalleri D, Wiseman S, et al. A randomized, controlled field study to assess the efficacy and safety of lotilaner flavored chewable tablets (Credelio ${ }^{\mathrm{TM}}$ ) in eliminating fleas in clientowned dogs in the USA. Parasit Vectors. 2017;10 1:528.

29. Meadows C, Guerino F, Sun F. A randomized, blinded, controlled USA field study to assess the use of fluralaner tablets in controlling canine flea infestations. Parasites \& Vectors. 2014;7 1:375.

30. Packianathan R, Colgan S, Hodge A, Davis K, Six RH, Maeder S. Efficacy and safety of sarolaner (Simparica(®)) in the treatment and control of naturally occurring flea infestations in dogs presented as veterinary patients in Australia. Parasit Vectors. 2017;10 1:387. 
31. Rohdich N, Roepke RKA, Zschiesche E. A randomized, blinded, controlled and multi-centered field study comparing the efficacy and safety of Bravecto ${ }^{\mathrm{TM}}$ (fluralaner) against Frontline ${ }^{\mathrm{TM}}$ (fipronil) in flea- and tick-infested dogs. Parasites \& Vectors. 2014;7 1:83.

32. Lavan R, Armstrong R, Burgio F, Tunceli K. Duration of annual canine flea and tick protection provided by dog owners in Spain. Parasit Vectors. 2018;11 1:458.

33. Lavan R, Armstrong R, Tunceli K, Normile D. Dog owner flea/tick medication purchases in the USA. Parasit Vectors. 2018;11 1:581.

34. Gates MC, Nolan TJ. Factors influencing heartworm, flea, and tick preventative use in patients presenting to a veterinary teaching hospital. Prev Vet Med. 2010;93 2-3:193-200.

35. Matos M, Alho AM, Owen SP, Nunes T, Madeira de Carvalho L. Parasite control practices and public perception of parasitic diseases: A survey of dog and cat owners. Preventive Veterinary Medicine. 2015;122 1:174-80.

36. Rust MK. The Biology and Ecology of Cat Fleas and Advancements in Their Pest Management: A Review. Insects. 2017;8 4.

37. Dryden MW, Payne PA. Biology and control of ticks infesting dogs and cats in North America. Vet Ther. 2004;5 2:139-54.

38. Halos L, Beugnet F, Cardoso L, Farkas R, Franc M, Guillot J, et al. Flea control failure? Myths and realities. Trends Parasitol. 2014;30 5:228-33.

39. Adams VJ, Campbell JR, Waldner CL, Dowling PM, Shmon CL. Evaluation of client compliance with short-term administration of antimicrobials to dogs. J Am Vet Med Assoc. 2005;226 4:567-74.

40. Barter LS, Watson AD, Maddison JE. Owner compliance with short term antimicrobial medication in dogs. Aust Vet J. 1996;74 4:277-80.

41. Claxton AJ, Cramer J, Pierce C. A systematic review of the associations between dose regimens and medication compliance. Clin Ther. 2001;23 8:1296-310.

42. Coleman Cl, Limone B, Sobieraj DM, Lee S, Roberts MS, Kaur R, et al. Dosing frequency and medication adherence in chronic disease. J Manag Care Pharm. 2012;18 7:527-39.

43. Kardas P. The DIACOM study (effect of Dosing frequency of oral Antidiabetic agents on the COMpliance and biochemical control of type 2 diabetes). Diabetes Obes Metab. 2005;7 6:722-8.

44. Brown MT, Bussell J, Dutta S, Davis K, Strong S, Mathew S. Medication Adherence: Truth and Consequences. Am J Med Sci. 2016;351 4:387-99.

45. Averell CM, Stanford RH, Laliberté F, Wu JW, Germain G, Duh MS. Medication adherence in patients with asthma using once-daily versus twice-daily ICS/LABAs. J Asthma. 2019:1-10.

46. Eisen SA, Miller DK, Woodward RS, Spitznagel E, Przybeck TR. The effect of prescribed daily dose frequency on patient medication compliance. Arch Intern Med. 1990;150 9:1881-4.

47. Iglay K, Cao X, Mavros P, Joshi K, Yu S, Tunceli K. Systematic Literature Review and Meta-analysis of Medication Adherence With Once-weekly Versus Once-daily Therapy. Clin Ther. 2015;37 8:1813-21.e1. 
48. Saini SD, Schoenfeld P, Kaulback K, Dubinsky MC. Effect of medication dosing frequency on adherence in chronic diseases. Am J Manag Care. 2009;15 6:e22-33.

49. Stanford RH, Averell C, Parker ED, Blauer-Peterson C, Reinsch TK, Buikema AR. Assessment of Adherence and Asthma Medication Ratio for a Once-Daily and Twice-Daily Inhaled Corticosteroid/Long-Acting $\beta$-Agonist for Asthma. J Allergy Clin Immunol Pract. 2019;7 5:1488-96.e7.

\section{Figures}

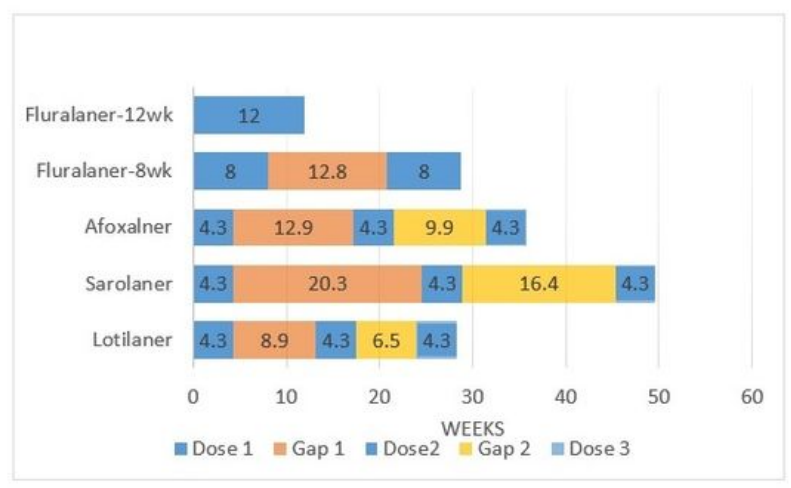

\begin{tabular}{|c|c|c|}
\hline Product & $\begin{array}{c}\text { 3 month } \\
\text { dosing period } \\
\text { including } \\
\text { average gap } \\
\text { duration } \\
\text { (weeks) }\end{array}$ & $\begin{array}{c}\text { \% of } \\
\text { period } \\
\text { protected }\end{array}$ \\
\hline $\begin{array}{c}\text { Fluralaner } \\
\text { Topical: } 12- \\
\text { week dosing }\end{array}$ & 12 & 100 \\
\hline $\begin{array}{c}\text { Fluralaner } \\
\text { Topical: 8-week } \\
\text { dosing }\end{array}$ & 28.8 & 56 \\
\hline Afoxolaner & 35.7 & 36 \\
\hline Sarolaner & 49.6 & 26 \\
\hline Lotilaner & 28.3 & 46 \\
\hline
\end{tabular}

a Fluralaner-12wk = fluralaner with 12-week dosing interval using 1 dose.

Fluralaner-8wk= fluralaner with 8-week dosing interval using 2 doses.

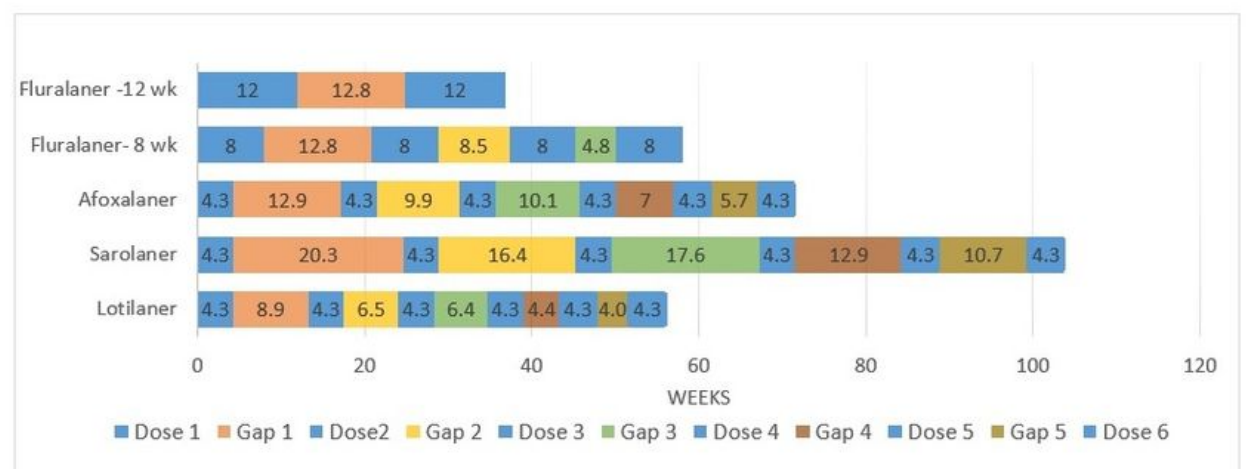

a Fluralaner-12wk = fluralaner with 12-week dosing interval using 2 doses.

Fluralaner-8wk= fluralaner with 8-week dosing interval using 4 doses.

\begin{tabular}{|c|c|c|}
\hline Product & $\begin{array}{c}\text { 6 month dosing } \\
\text { period including } \\
\text { average gap duration } \\
\text { (weeks) }\end{array}$ & $\begin{array}{c}\text { \% of period } \\
\text { protected }\end{array}$ \\
\hline $\begin{array}{c}\text { Fluralaner Topical: } \\
\text { 12-week dosing }\end{array}$ & 36.8 & 65 \\
\hline $\begin{array}{c}\text { Fluralaner Topical: } \\
\text { 8-week dosing }\end{array}$ & 58.1 & 55 \\
\hline Afoxolaner & 71.4 & 36 \\
\hline Sarolaner & 103.6 & 25 \\
\hline Lotilaner & 56.0 & 46 \\
\hline
\end{tabular}

\section{Figure 1}

Impact of ectoparasiticide purchase gaps on the percent of time protected. a. Impact of purchase gap when up to 3 months of ectoparasite protection is purchased with gaps. a b. Impact of purchase gaps when up to 6 months of 
ectoparasite protection is purchased with gaps a

\section{Supplementary Files}

This is a list of supplementary files associated with this preprint. Click to download.

- GraphicalAbstractK9Gap.docx 